\title{
Person, persona and personality modification: An in-depth qualitative exploration of quantitative findings
}

\section{Dawn Querstret}

School of Psychology, University of Surrey

d.querstret@surrey.ac.uk

\author{
Oliver Robinson
}

Dept of Psychology, University of Greenwich o.c.robinson@gre.ac.uk

\begin{abstract}
Quantitative and qualitative methods can work productively together to explore the conundrum of personality. In this study, a personality questionnaire tool (TIPI3C) was used to screen for participants with high levels of personality variability across three social contexts. 112 participants completed the questionnaire, which assesses the Big-Five traits as they manifest when with parents, friends and work colleagues. 8 participants, between the ages of 20 and 40, whose scores categorised them as high in personality variability, were then interviewed using semi-structured interviews. Transcripts were analysed using Thematic Analysis. Participants described personality modification through the adoption of social personae. Motivations for this included a) to make a good impression; b) to protect and suppress emotions and c) due to a fear of rejection and social anxiety. Adopting personae was related to feelings of anxiety and insecurity, while acting in line with one's own personality was described as relaxing and preferable. The mixed-methods study shows how qualitative methods can be used to dig underneath quantitative findings to help explain and account for them.
\end{abstract}

Keywords: persona, personality, personality modification, social context, mixed-methods, thematic analysis

The psychology of personality has, ironically, a split personality. On the one side sits trait theory with its preference for quantitative assessment tools, and research that employs group-aggregation to study linear associations and group differences in trait variables. On the other side is located an ever-growing body of qualitative research about the narrative and socially-constructed aspects of human character, which include gendered, storied and contextually-sensitive studies of personality and identity (Barresi \& Juckes, 1997; Gergen, 1972; McAdams, 2006; Sanford, 1956).

This institutionalised split has led to a division of terms - the term 'personality' has increasingly been co-opted as a quantitative term, while the qualitative approach has preferred the terms 'self', 'identity' and 'life story' (Burr, 1995). The result of this split is that the word personality has largely disappeared from the vernacular and discourse of qualitative researchers. However it is important to remember that there is nothing intrinsically quantitative about the notion of personality. The numerical assessments of trait theory provide highly simplified outlines of personality, while deeper beliefs, defining life events, values, preferences, aspirations, private fantasies and hidden weaknesses remain out of view.

Following Sanford (1956) and Bornstein (2007), the terms 'surface' and 'depth' are used in this paper to convey the difference between the immediately divulged, public dimensions of personality that can be conveyed consciously and simply in language by the use of trait or goal terms ('surface' of personality), and those aspects of personality that are less accessible, more 
private, less frequently disclosed and more complex to describe ('depth' of personality). The term 'digging' is used to metaphorically imply the progressive movement from surface to depth in assessment and analysis.

Moving from surface to depth in personality research can be achieved through the creative combination of quantitative assessment tools and qualitative techniques. There has been an understandable reluctance to combine quantitative techniques with qualitative methods, for qualitative psychology in Europe has generally been critical of the essentialist / mechanistic assumptions that it sees as underpinning quantitative methods, and has positioned itself as an alternative way of doing psychology, rather than as a complement to quantitative methods ${ }^{1}$. However the growing mixed-methods movement suggests a middle-ground is both possible and fruitful without corrupting the essence of qualitative enquiry. There are now recognised research designs and evaluative criteria for designs that bring quantitative and qualitative data into mutually-formative combinations (Creswell \& Plano Clark, 2007).

The current study is, according to our knowledge, one of the first to attempt mixing quantitative and qualitative methods in the area of personality research. The specific research design we employ is called an 'embedded explanatory' mixed-methods design (Creswell \& Plano Clark, 2007) - it uses qualitative methods to explore and "dig beneath" quantitative data. We appreciate that idea of starting a qualitative study with a set of numbers may be anathema to some researchers, but we hope that the findings from this exploratory study show that the approach elicits interesting, unusual and useful information. The study inevitably sits somewhere in between trait and narrative/social constructionist perspectives of personality and identity, and so in order to provide a framework for interpreting our findings, both approaches are reviewed below, prior to highlighting how they both inform the current study.

\section{Quantitative Research on the Interaction of Personality and Social Context}

The current study explores how, why and in what way people vary their personality to adapt to different social contexts and how this is experienced. Quantitative studies have attempted to explore this in a variety of ways. One way has been asking people to numerically rate their personality traits as they manifest in different social contexts. This has generally shown both individual and mean-level variability in trait expression between contexts, both when they rate it retrospectively (Block, 1961; Donahue and Harary, 1998; Robinson, 2009) and when they rate behaviour while actually in the contexts in question (Heller, Watson, Komar, Min \& Perunovic, 2007). This 'cross-context personality variability' is paradoxically systematic; people generally rate themselves as more extraverted, agreeable and open when with friends, more conscientious at work and more neurotic around parents (Roberts \& Donahue, 1994; Donahue \& Harary, 1998; Robinson, 2009; Robinson, Wright \& Kendall, 2011). Studies have shown that personality variability is related to lower self-esteem (Sheldon et al., 1997), more anxiety (Diehl, Hastings and Stanton, 2001), more depression (Block, 1961; Lutz and Ross, 2003), lower life-satisfaction (Suh, 2002), lower role-satisfaction (Donahue et al., 1993), poorer physical health (Cross, Gore and Morris, 2003) and poorer attachment to parents (Robinson, Wright \& Kendall, 2011).

Another way of quantitatively studying the effect of social context on behaviour is using experience sampling (Fleeson, 2001; Fleeson, 2004). In studies that have employed this method, individuals rate their concurrent behaviour at random times during the day and also state the

\footnotetext{
${ }^{1}$ This is considerably less true in American / Canadian psychology, where qualitative data is still usually quantified and there is less of an identifiable qualitative psychology movement.
} 
social context that they are in. The data is then analysed to view how people's behavioural, interpersonal and emotional tendencies are affected by context. The overall findings are that while situations influence how we behave, over time each person has a clear 'central tendency' to behave in a particular way despite the contextual flux (Fleeson, 2004). This research has provided a way of reconciling the old 'person vs. situation' debate by way of concluding on momentary variability but long-term stability, but has provided little information about how changing habits, preferences and dispositions relate to personal motives to 'fit in' to social context and to be accepted.

Social cognitive theorist Walter Mischel has been at the forefront of debates surrounding the roles of personality and situation in determining behaviour, and developed a 'cognitiveaffective personality system' (CAPS) theory that specifies how stable patterns of behaviour emerge as a function of cognitive factors, affects and situations (Mischel, 1999; Cervone, 2005). As with so many cognitively-based theories, it employs mechanistic/computation language to convey its key concepts. It specifies five 'cognitive-affective units'; encoding strategies, selfregulation competencies, expectancies, goals and affects. Situational variability is seen as a function of if (situation) -then (response) cognitive-affective computations, and people are viewed as having definable 'if-then signatures'. A limitation of the theory is that it was developed a priori to collecting data on it, rather than inductively through the experiences and accounts of why and how people vary their personality and behaviour in different social situations. When people give their accounts of the process of socially-mediated personality change, their accounts do not conform to linear rationality of an if-then risk analysis.

Quantitative methods, whether questionnaire-based or experimental, are hampered by their very nature when trying to assess and explore individual personalities, for they must aggregate data from a sample together into means and variance for analysis purposes. This has led to the sardonic accusation that trait theory is more group-sameness psychology than individual differences psychology (Bannister \& Fransella, 1986). Theories such as Mischel's CAPS theory are arguably stuck in between group-aggregated laboratory experimental data, and a claim to contextual sensitivity. Qualitative methods, on the other hand, employ smaller, purposively selected samples and are able to present a person within his/her lived context and life history more adequately.

\section{Qualitative Research on Personality and Social Context}

The social and contextual influences on human identity and personality have been a central concern to qualitative researchers since the genesis of qualitative method and its working partnership with epistemologies such as social constructionism and critical theory. Prior to the formal advent of qualitative methods in the 1980s, clinical research and theory were concerned with the question of why people may develop fragmented identities or personalities. Jung (1921, 1928 ) proposed that adults use personae - social fronts aimed at concealing socially inappropriate aspects of personality, and/or adopting the normative customs and habits of a particular social role or subculture. Similar constructs have been employed in the clinical literature since Jung Riviere talked of public displays of femininity in women as a "masquerade" designed to hide their wish for masculinity (1929), Perlman (1968) linked the persona with social role theory, while Laing (1960) developed a theory of the false self which stated that habitually employing false selves / personae leads to psychological ill-health. The issue of whether personae and false selves are healthy or not may relate to their extent of use - Winnicott (1960) distinguished levels of false self, from the normal and healthy (i.e. being polite and tactful, appropriate social disclosure), 
through to the pathological (never voicing personal preferences, values or opinions and living permanently according to the expectations of others).

The dialectical counterpoint to the persona/false self is the authentic self, or the state of / experience of authenticity. Both Maslow and Rogers wrote of authenticity as an ideal of adult development (Maslow, 1968; Rogers, 1959). Authenticity is living in a way where one gives voice to one's own feelings, opinions and values in social situations, even if they may not meet with social approval (Harter, Bresnick, Bouchey \& Whitesell, 1997); and acting spontaneously according to self-determined motives and personal interests (Deci and Ryan, 1991). The authentic state is described in everyday language as 'being myself', or 'being natural' and has been found to be more conducive to mental health and more satisfying than persona-based identity (Rowan, 1988; Rogers, 1961; Winnicott, 1960). Recent qualitative research on authenticity and the use of false selves suggests that personality development is viewed by young adults as progressing towards an 'authentic' expression and away from 'false' behaviours that are employed to conform and suppress beliefs, interests and feelings (Robinson \& Smith, 2010b).

The social constructionist approach to understanding personality views social masks as both inevitable and desirable. Sociologist Erving Goffman (1959) concluded from his research on face-to-face communication that human beings are constantly managing the impression they make on others, avoiding embarrassment and conducting a kind of theatrical social performance. The metaphor he used to describe the difference between public and private aspects of self was the theatre, which has both on-stage and off-stage activity (a parallel of the surface-depth metaphor used in the current study). This idea is paralleled by the idea of 'performativity', popularised by philosopher Judith Butler (1997), who suggested that gender is a performance with a script that is rehearsed over time much as actors rehearse their lines.

Social constructionists view the self and personality as inherently relational, fragmented and existent between persons, rather than in persons. Gergen suggests that all people wear multiple masks to manage social interactions, and that persons hide a 'back region' of self from public view, to avoid social rejection and disapproval (Gergen, 1972). The self is manifest within relationships - there is no true self, or absolute personality, instead there is a nexus of relationships and commitments to self-disclosure (Gergen, 2009). Burr (1995) suggests that words used to describe ourselves (e.g. friendly, agreeable, shy) do not in fact refer to interior traits but refer to relationships. She suggests avoiding the term personality, with its essentialist connotations of being fixed, interior and self-existing, in favour of the term identity.

Sampson (1993) suggests that locating personality within persons reinforces the individualist assumptions of Western culture. If a person is unhappy and sees the problem as a result of their personality (e.g. a protester being diagnosed with antisocial personality disorder), the socio-political system is then absolved of blame. This legitimises a system that may be biased towards minority groups or those who do not have a political voice. Feminist theory further states that notions of self and personality have been masculinised - the ideals of autonomy and individuation that characterise the mature self in Jungian theory and a variety of modern personality theories reflect this gender bias (Gilligan, 1982). The feminist perspective sees the mature self as embedded in and defined by relationships; as a connective node rather than a discrete entity. In this way it is closely aligned to the social constructionist movement (Meyers, 1989). 


\section{The current study}

Quantitative personality assessment is here to stay. Millions of people and organisations worldwide employ tests such at the Myers Briggs Test in career development, training and selfdevelopment to give a broad-brush numerical profile of personality traits and types. Qualitative psychologists can either look the other way or attempt to engage with this increasingly powerful scientific school. The current study aims to do just that, by employing interviews and thematic analysis to explore the meaning of data elicited through a questionnaire that assesses cross-context personality variability. Questionnaires provide abstracted and simplified personality data, and the quantitative paradigm has correspondingly been referred to as 'the psychology of the stranger', for the assessment tools provide no more information about a person than a stranger would glean in a short encounter (McAdams, 1994). Using a mixed-methods approach allowed us to a) explore what people mean and refer to by the numbers they give in a questionnaire, and b) move progressively from surface to depth. The numbers were used as a starting point, as a topological map to guide qualitative digging and delving.

The current study, being a hybrid, had both a hypothesis and research question. The research question was - what are the motivations for, and experiences of, having a socially variable personality? The prediction was that quantitative personality variability would prove to be related to, and indicative of, the variable use of social personae in particular contexts.

\section{Method}

\section{Participants and 'extreme case' sampling procedure}

In order to identify individuals for interview, an 'extreme case' sampling strategy (where cases are selected because of their high or low scores on a variable of interest) was employed (Gerring, 2007). We aimed to interview participants who reported a high level of personality variability, to explore how, why and in what way these individuals vary their personality when in different social contexts. 112 participants ( 75 females; 37 males) with an age range of 21-57 years $(\mathrm{M}=31.46 ; \mathrm{SD}=6.03)$ were drawn from mature part-time Psychology students at the University of London; and from an amateur running club on the outskirts of London.

All participants were supplied with a participant information sheet; two copies of the consent form; a participant debrief sheet; and the Ten Item Personality Inventory (TIPI 3-C) which is a self-report questionnaire that assesses how the Big 5 personality traits manifest in three life contexts; with parents, with friends and with work colleagues (Robinson, 2009). Participants were asked to read the information sheet and then to complete the two copies of the consent form (one for their records and one to be returned to the researcher), in which they were asked for the following information: Age; Gender; whether English is their first language (yes, no); would they be interested in taking part in a follow-up interview (yes, no); Name; Signature; and Email Address (optional, if interested in follow-up interview). Participants then completed the questionnaire which took approximately 10 minutes.

There were no restrictions placed on completing the questionnaire other than a requirement of being between the ages of 20 and 40 . This age range was chosen for the study as personality variation and persona-related phenomena are saliently different before and after midlife (Hollis, 1993), so a pre-midlife adulthood sample was selected. Participants from the University of London were approached during evening lectures and participants from the running club were approached after a weekend training session. It was required that participants' first language was English. 
For each of the 112 participants, a personality variability index (PVI) was calculated from the scores they provided on the TIPI 3C. The higher a person's PVI, the higher the cross-context variability of their personality as they reported it in the three contexts measured (see Appendix A for calculation procedure). Participants were eligible for interview if their PVI score was one standard deviation or more above the mean $(\mathrm{M}=33.50 ; \mathrm{SD}=17.26)$. In order to fulfil the quota for interview, those whose PVI scores were close to one standard deviation above the mean were also approached. 8 individuals were recruited for interview (5 females, 3 males) with an age range of 31-40 years $(\mathrm{M}=36 ; \mathrm{SD}=3.12)$. Four of the participants were mature part-time Psychology students; Amy, Mary, Steven \& Trudy. The other four participants were members of the running club: Brandon, Frankie, Lily \& Malcolm. All participants were Caucasian, native English speakers and born in Britain. Details of the eight participants are included in Table 1.

\section{INSERT TABLE 1 HERE}

The TIPI-3C questionnaire identified individuals who showed a high tendency to change their personality depending on who they are with, and provided a starting point for focusing interview questioning. This article described results elicited from the resulting interviews.

\section{Interviews}

Participants were interviewed using a semi-structured interview guide, which was designed in such a way as to demonstrate sensitivity to participants' perspectives through the construction of open-ended and non-directive questions. The intention was to enable participants to respond freely (Wilkinson, Joffe, \& Yardley, 2004); and to provide rich or 'thick' (Geertz, 1973) descriptive accounts of their experience of personality across different social contexts. Each interview guide was created bespoke for each participant. In the interview guide questions were first asked about the participants' scores on the questionnaire measure across three social contexts (with parents, with friends, and with work colleagues) for each of the ten personality items in the TIPI-3C; then explored how participants experienced each of the social contexts and how they would describe themselves in each context; and finally focussed on the experience of authenticity or falsity in the three contexts. See Appendix A for an example bespoke interview guide. Each interview lasted approximately one hour and was transcribed in full by the first author.

All 8 participants were interviewed by the researcher and could choose to be interviewed either in an interview room at the University of London, in their own home, or at the residence of the researcher (see Table 1 for locations). The only stipulation was that it be a quiet environment with minimal distractions. At the beginning of the interview, participants signed a consent form. The interview process was explained to participants; and they were told that the interviews would be recorded and later transcribed word-for-word into an interview transcript which would be analysed by the first author and reviewed by the second author. Participants were assured that all names and places would be changed to protect their anonymity; and that the audio file would only be accessible to the researcher. Participants were also assured that it was their right, at any time, to stop the interview and that if there were any questions that they did not feel comfortable answering, they could choose not to answer. A participant debrief sheet was given to each participant as they left. 


\section{Thematic Analysis}

Transcribed interviews were analysed using Thematic Analysis (Braun \& Clarke, 2006). Thematic Analysis is a method for identifying and analysing thematic patterns within data (Borrell, 2008). Semantic themes describe and account for the participant's verbal output, while latent themes describe underlying concepts; and relationships between themes are explored to develop an integrated analysis. Due to its relative independence from any specific epistemology, Thematic Analysis provides a flexible and useful research tool (Braun \& Clarke, 2006), and is ideal for a mixed methods study. For this study, Thematic Analysis was carried out within a critical realism framework, by focussing on the ways in which participants made meaning of their experiences and how the broader social context impacted on those meanings (Borrell, 2008).

Initially each interview transcript was read and re-read multiple times to enable the researcher to connect with, and be focussed on, the participant. The next step involved noting anything of interest in the margins of the script including semantic, content or latent features of the data. Next, the noted comments were reviewed and themes were identified. At this stage, in order to ensure the connection between the participant's own words and the researcher's interpretation was not lost, the original transcript was constantly revisited. Connections were sought between all emergent themes. Themes were mapped to each other and merged where necessary and a table of themes for the participant, complete with evidentiary quotes from the original transcript, was created. Each participant transcript was analysed using the same process and after all participant scripts had been individually analysed, connections were identified between themes across participants for the main themes of the study. As report writing progressed, analytical themes were revisited to ensure coherence and consistency (Braun \& Clarke, 2006). The two authors of the current article worked on the analysis together to check the progress at each stage, with the lead author as primary analyst and second author as secondary analyst.

\section{Results}

\section{Personae in one context or more}

As predicted, the use of social personae was a key explanation for, and experience of, personality variability in all 8 cases. Personae were personality adaptations created to adapt to the challenges of social contexts. 4 (50\%) of the participants (Lily, Amy, Trudy, and Frankie) adopted a persona when with their parents. 5 (63\%) of the participants (Mary, Malcolm, Brandon, Frankie and Steven) employed a persona at work. Just 2 (25\% - Mary and Lily) identified using a persona when with their friends. Therefore 5 identified one social context within which they moderated their personality (Malcolm, Brandon, Amy, Steven, and Trudy); and 3 identified two social contexts within which they moderated their personality (Mary, Lily, and Frankie). Different motivations for employing personae were described: performance/making a good impression, emotional protection, social anxiety and fear of rejection. These are outlined below.

\section{The emotional experience of personality modification}

All eight participants were conscious of being more or less close to their natural personality (and therefore more or less authentic) in particular contexts. This was a salient part of the affective experience of personality change in all 8 cases. The experience of moving away from their own personality was associated with effort, frustration, vigilance and anxiety. For example, at work Frankie was “repressed, and annoyed that I can't just be, feel, you know, myself and talk about 
whatever I want to talk about" (Frankie, p.2). Likewise, Mary described maintaining a persona in her city job as tiring:

"It is tiring and it's tiring to keep a mask up all the time [pause] and I mean that because it's so conscious, some of the time it is, it's not something I want to do but it's like, you've already, it's like you're on a treadmill and you can't stop otherwise you'll fall off." (Mary, p.31)

In Amy's account the effort involved in maintaining a persona was obvious and she described a need to be vigilant in order to keep track of the person she pretended to be with her parents.

"It's such an effort not to be authentic, it makes life so difficult and then you, sort of, have to remember not what you've said because you've been lying but [pause], you know, my mum doesn't know hardly anything about my life these days and it's hard to remember what she doesn't know and it's, oh, it's just too much effort. And life is hard enough with such a, you know, transitional lifestyle. Life is hard enough without having to think "right, what do I, what sort of effort do I have to make today, you know, who am I going to be today?"..." (Amy, p.21)

Mary and Amy's accounts captured best the sense of emotional exhaustion associated with maintaining a persona. Conversely, in the social contexts in which participants described being able to act in line with their own personality, they described feeling relaxed, confident, calm and comfortable. For example, Steven describes having to adopt a persona at work, but when he is with his parents, there is no such requirement, and this he finds positive:

"When I'm with my parents I'm just their son. So I don't have a role so much to play. Oh well, there is the role of the son but it's not a role that, they're going to love me either way, you know, whether I'm good, bad or ugly." (Steven, p. 9)

While Steven spoke of being close to his natural personality with his parents, the context most commonly ascribed as facilitating authentic self-expression was with friends. For example, Trudy spoke of being herself, and therefore more relaxed and supported, when with her friends:

"I suppose I'm more myself when I'm with my friends than when I'm with my parents. Um, I feel more confident when I'm with my friends than I do when I'm with my parents. Um, I feel more supported when I'm with my friends than when I'm with my parents. So, I just feel more relaxed so I'm more myself."' (Trudy, p.1)

\section{Performance/making a good impression}

Seven participants (see Table 1) described moderating their personality in order to make a good impression. For Mary, this meant suppressing parts of her personality at work and when with her friends:

'Um, it's quite a different culture to what I'm used to from home and from, what I'm used to where I've been before. Um, it's an American company, very, uh [pause], conservative, um, in some ways, like, they're very religious, a lot of the people. So I do feel as though I have to watch everything I say which means I can't show enthusiasm to the extent that I want and in the way that I want." (Mary, p.1)

"My friends are also not that tolerant of, like, moodiness, or being down emotionally, or anxious. I mean a lot of them see it as a failure, and there's a sort of stigma too, being a bit highly strung. You're held to a standard." (Mary p, 17) 
Steven's motivation for adopting an outwardly calm and organised persona was to appear as capable as possible at work:

"While I'm calm, and while I'm organised, um, um, and all the other ones that we've said work was high rated, um, they're all the things that make me capable, or make me feel capable, well it's how I maintain appearing capable because if I'm incapable I'll be in a bad place again." (Steven, p.12)

While Steven and Mary spoke of suppressing perceived negatives; for Malcolm, a TV weather man, it was the opposite experience. He describes the importance of always making a good impression in his work role and emphasising positivity and enthusiasm, even when he didn't feel that way:

"I just have to sort of impress the company people to make sure, just to keep your profile high, and, you know, they're the people you've got to impress and they're the people, you know, the ones that decide what shifts you do and what broadcasts you do. So you've got to keep them happy....being enthusiastic is quite important on air, because if you let your on-air screen drop just by a little bit the TV really magnifies that, so, if you're a little bit down, you can do a really flat broadcast and no one is going to be watching, and then that will get noted." (Malcolm, p.3)

For Malcolm, the consequences of not adopting his work persona were very salient and a motivating factor - at best, he would not get preferable broadcast slots and at worst, he could lose his job.

Several participants also described trying to make a good impression when with friends. Police support officer Brandon emphasised making two different kinds of impression when with friends and when at work. When with friends, he describes consciously trying to be perceived as 'nice':

"But I'd like to be known as 'nice bloke Brandon', if I'm honest, that's the way I like to be perceived. And I probably lead some of my life in that respect, trying to accomplish that." (Brandon, p.30)

However, when he is at work he puts on a very different kind of personality - stern and authoritative:

"Yeah, I'm a community officer so I deal with kids. Um, if I go down to a shop that's suffering with um, antisocial behaviour all the time, I'll go down there and I will be stern, I'll be stern. So with the slag [colloquial expression for community youths], there is, you know, there won't be an argument. "You will do what I will say because I'm in a position of authority and you will do it", because if I lose or back down from that statement, I'm then undermined." (Brandon, p.12)

Brandon's invocation of different personas was conscious and intentional but not all participants controlled the adoption of persona in such a tactical way.

\section{Concealment: Emotional protection and suppression}

Seven out of the eight participants described adopting a persona for the purposes of emotional protection when with parents, or in some cases when at work. For example, Steven describes protective emotional barriers at work that help him work in this stressful environment:

"It just seems to work better if I can put barriers round, you know, almost a protective cloak round myself and say "right, I won't let work feel emotions", and then I won't 
possibly open up too much and then horrible things happen. I think that's possibly why I am the way I am. You know, it's a self-preservation type thing." (Steven, p.18)

In contrast, Frankie describes altering her personality completely when she is with her parents, and describes how this relates to having long-term problems in her relationship with her parents, and a history of emotional conflict. She describes becoming more passive and withdrawn, and her motivation is 'self-preservation':

"I wouldn't call it so much a front as almost like self-preservation, you know, it's like, it's just the way that we are, it's the way that I am with them, it's not, I can't be any other way. It's not like I'm pretending to be like that, um, it's almost like a subconscious thing, it's just the way that it is." (Frankie, p.22)

Like Frankie, Trudy and Amy both describe difficulty opening up and confronting issues with their parents, and withdraw as a result. For example, Trudy describes a careful self-censorship when she is with her parents:

"Because I think it would be too negative. Because I think if it started, it would never stop, because there's so much turbulence there and there's been so much hurt there and so much, um, need, um [pause], a need to fight, things, I just think it would be very, very destructive. I've worked so hard to try and keep things [pause] stable, and even I think if I started unlocking all the skeletons [laughing] I don't think I would be able to cope actually." (Trudy, p.16)

This she links back to ongoing difficulties in her relationship with her mother:

“...my mother had always told me that I was stupid. And I think if you've had that, sort of, since you can walk and talk, that you're stupid and incapable, you kind of, it's very difficult to, to leave it behind, when you've had it from your mother." (Trudy, p.3)

Where Trudy's self-censorship is intentional, Amy describes a more involuntary process of becoming more withdrawn when she is around her family:

"So it's really interesting that, on the very, very rare occasion that, I see anybody from my family, um, then my whole character changes back to how I was and I'm sort of really insecure, really shy, just waiting to be told off all the time. Um, so yeah, sort of, parts of being an extravert will, sort of, come out but it will be so squashed by them, yeah, that I just become more withdrawn." (Amy, p.1)

\section{Social Anxiety and Fear of Rejection}

All participants described feeling socially anxious in particular contexts, and stated that this manifested as worry and concern at the prospect of being rejected. For example, Mary describes how she thinks that if she acts naturally with her friends and is more emotionally open, that may lead to social isolation and 'getting left behind'; and Frankie describes lacking confidence at work and feeling very socially anxious in meetings:

"Um, probably anxious [pause] you know, anxious in meeting situations. Probably, um, not very confident, so, you know, it effects my confidence and [pause] I think it also [pause], it makes me ramble like a ridiculous rambling, almost like I'm trying to convince people I know what I'm talking about, and so they mustn't think "what are you doing?"." (Frankie, p.22) 
Lily found herself constantly worrying about what she could say and how she would be perceived, resulting in constantly changing her behaviour to ensure acceptance:

"And I think when I'm most comfortable is when I'm on my own, that's when I'm most comfortable. Because then I'm not having to worry about anything, not having to worry at all about other people, about what they think. I think I do worry about that, more so than, it amazes me how some people can just do things and just go through life, and they don't even seem to think about it." (Lily, p.27)

\section{Malcolm - an example of functional personality modification}

Malcolm's case was different from the other 7 participants, insofar as his experience of varying his personality to fit it was not associated with social anxiety, low self-confidence or a sense of unwanted falsity. He was explicit that he moderated his personality in order to adapt to his job on television, and had no problem with this. In other interviews, the experience of adopting fronts and modulating one's natural personality was a more pathological account, related to problematic relationships, or ongoing insecurities or active mental health problems. Malcolm is testament to the fact that a work persona is not a problem per se. Personae can becomes dysfunctional, but are not necessarily so (Robinson \& Smith, 2010b).

\section{Discussion}

The research question that shaped this study was - what are the motivations for, and experiences of, having a socially variable personality? An associated prediction was that the quantitative phenomenon of personality variability would prove to be related to the variable use of social personae in particular contexts, and this hypothesis was supported.

The interview data point towards a number of motivations for social personality modification: performance/making a good impression, emotional concealment and fear of rejection / social anxiety. Personality modifications took the form of adopting impressive behaviours and concealment of aspects of personality, much as Goffman (1959) would have predicted from his studies of human interaction or Butler from her research on gender expression (Butler, 1997). Participants were mostly able to reflect on when such behaviours were a departure from their own personality and preferences and when they weren't, therefore performative and theatrical interactions may be optional rather than inherent in human personality.

Since Jung the persona has been viewed as a social construction that conceals the contradictions and issues that lie under the surface of personality (Hopcke, 1995: Robinson and Smith, 2010b). For half the sample, the concealing aspect of personality modification was employed to avoid conflict or emotional manipulation when with parents. These participants talked of withdrawing, suppressing opinions or shutting down when with their parents. This modification of normal behaviour was aimed at maintaining a harmonious environment and preventing disclosure of information or affect that could be manipulated in an environment that has a history of conflict - it therefore is a protective change. It supports the idea that variable personality expression in adults links to problematic and conflictual relationships with parents (Winnicott, 1960 Robinson et al., 2011).

As well as the concealing modifications described by participants, adoption of particular behaviours for the purposes of socially impressive performativity were also in evidence, akin to descriptions by Butler (1997), Goffman (1959), Riviere (1929) and Leary and Kowalski (1990). For example, respondents described adapting to the accepted behavioural repertoire of their social 
group or workplace in order to smooth social interaction and enhance the perceived chances of success. This side of personality modification is aligned with theories that propose social actions to be motivated, rehearsed public performances rather than passive expressions of dispositional traits (Butler, 1997; Goffman, 1959). When both the concealing / protective functions, combined with the adaptive / performative functions of personality change, are understood, a more comprehensive understanding of the phenomenon of contextual personality change is achieved.

There is a lack of agreement in existing literature about whether having a socially variable personality is beneficial or detrimental to wellbeing. Some theorists propose that variability across social contexts is adaptive, enabling people to respond flexibly to changing demands of different social contexts (e.g., Gergen, 1972; Paulhus \& Malcolm, 1988). On the other hand, theorists have suggested that variability across social contexts is maladaptive and suggestive of a weak and vulnerable sense of self (e.g., Leary, 2003; Maslow, 1968; Baird, Le \& Lucas, 2006; Rogers, 1959; Block, 1961). The current study suggests that the reality is somewhere in the middle - that the process of personality modification involves both negatives and positives. The negatives involve the affective corollaries of anxiety, social vigilance and feeling dishonest that come with adopting false personalities. The positives include the capacity to adapt to different social environments at home or at work (which may require quite different behavioural repertoires) and also the capacity to selectively perform in situations where that helps to succeed. A further positive is that the adoption of personae for some participants (e.g., Steven, Mary, Frankie, Trudy) clearly operated to protect a vulnerable psyche.

\section{Reflections on method}

The current study has demonstrated that the simplified data gained from a quantitative questionnaire can act as a useful starting point for interviews, and that underneath the apparent simplicities of numerical questionnaire data there is a complex and conflicting set of motives, affects and cognitions, personal and social adaptations, as well as meaningful links to past experiences.

Inevitably, compromises have to be made to build bridges - it is impossible to be as inductive as some qualitative researchers would like when employing a questionnaire to sample participants and shape interviews, however there is still scope for great thematic and emergent data exploration within the parameters that are set by this kind of method. The current study employed both a specific hypothesis and a general aim, and this reflected its hybrid nature theory-influenced yet exploratory.

A positive novelty of the mixed-methods approach used here is that it places the quantitative data subordinate to the qualitative data - the questionnaire and normative dataset help to purposively select participants and to focus the interview questions, but the qualitative phase provides the substance of the analysis. This inverts the commonly-held but incorrect notion that qualitative research is the exploratory underling of the quantitative paradigm in mixed-methods designs (Hanson et al., 2005). Indeed, this study suggests that quantitative data are at best a starting point, rather than a conclusion - a fact that undermines the solely quantitative analysis of human identities and personalities.

The conclusions to this study are provisional and tentative. Firstly, the questionnaire, the TIPI-3C, only considers personality variability across three social contexts - with parents, friends and work colleagues - but does not elicit data on personality in the partner / spouse context or other contexts. However the interview was not limited to the questionnaire data, even though the 
numbers provided a concrete starting point for discussion, thus experiences in other contexts could be explored and were explored.

Other limitations are inherent in the sample- only 8 individuals were interviewed and analysed out of the 112 who completed the questionnaire, and these were those with high levels of personality variability. Given the constraints of reporting rich interview data and themes within the scope of a journal article such as this, a larger sample would have made it difficult to convey the data without losing a sense of the individual people in the analysis (Robinson \& Smith, 2010a). However, research in other demographic and psychologically-defined samples is essential.

\section{Suggestions for future research and conclusions}

This study builds a bridge between areas of literature that have previously not touched upon each other - the quantitative literature on social personality variability and the clinical / humanistic / qualitative literature on persona and social performance. It managed this by creatively mixing methods - using interviews to dig beneath cross-context personality data elicited from a questionnaire. Increasingly in Psychology, there are calls for the effective synthesis of qualitative and quantitative methods in Psychology through mixed-methods research (Hanson et al., 2005; Mertens, 2003; Yardley \& Bishop, 2007). The creative combination of quantitative and qualitative methods leads research down new and interesting paths, and correspondingly the current study has no direct precedent, either in design or findings.

The data from this study suggest a variety of directions for future research. Questions that arose from, but were not answered by, the data include: What is the link between early familial relationships and adult personality variability / personae usage? What are the experiences and motivations of those very low in personality variability - are they able to reflect on why they don't change their personality depending on who they are with? Is there a difference in the personality modification process between men and women that this study did not pick up on because of the low number of participants?

A final question with wide methodological implications is - can data from other questionnaires be dug into in the way that we have managed in this study? If so, this would provide a new, integrative avenue of research for all areas of Psychology, right at the interface of quantitative and qualitative schools. This is an interesting prospect - one which is waiting to be fully explored. 
Querstret and Robinson. Qualitative Research in Psychology, in press.

\section{References}

Baird, B. M., Le, K, \& Lucas, R. E. 2006: On the Nature of Intraindividual Personality Variability: Reliability, Validity, and Associations with Well-Being. Journal of Personality and Social Psychology, 90, 512-527.

Bannister, D \& Fransella, F. 1986: Inquiring Man: The Psychology of Personal Constructs, 3rd Edition. London: Croon Helm.

Barresi, J. \& Juckes, T.J. 1997: Personology and the Narrative Interpretation of Lives. Journal of Personality, 693-719.

Block, J. 1961: Ego Identity, Role Variability, and Adjustment. Journal of Consulting Psychology, 25, 392-397.

Bornstein, R.F. 2007: From Surface to Depth: Diagnosis and assessment in personality pathology. Clinical Psychology: Science and Practice, 14, 99-102.

Borrell, J. 2008: A thematic analysis identifying concepts of problem gambling agency: with preliminary exploration of discourses in selected industry and research documents. Journal of Gambling Issues, 22, 195-218.

Braun, V., \& Clarke, V. 2006: Using Thematic Analysis in Psychology. Qualitative Research in Psychology, 3, 77-101.

Burr, V. 1995: An Introduction to Social Constructionism. London: Routledge.

Butler, J. 1997: Excitable Speech: Politics and the Performative. London: Routledge.

Cervone, D. 2005: Personality architecture: Within-person structures and processes. Annual Review of Psychology, 56, 423-452.

Creswell, J.W. \& Plano Clark, V.L. 2007: Designing and conducting mixed methods research. London: Sage.

Cross, S.E., Gore, J.S. \& Morris, M.L. 2003: The Relational-Interdependent Self-Construal, SelfConcept Consistency and Well-Being. Journal of Personality and Social Psychology, 85, 933-944.

Deci, E.L. and Ryan, R.M. 1991: A motivational approach to self: Integration in personality. In:

R. Dienstbier, Ed. Nebraska symposium on motivation: Perspectives on motivation Vol. 38, pp. 237-288, University of Nebraska Press, Lincoln, NE.

Diehl, M., Hastings, C. T., \& Stanton, J. M. 2001: Self-concept differentiation across the adult life span. Psychology and Aging, 16, 643-654.

Donahue, E. M., \& Harary, K. 1998: The patterned inconsistency of traits: Mapping the differential effects of social roles on self-perceptions of the Big Five. Personality and Social Psychology Bulletin, 24, 610-619.

Donahue, E. M., Robins, R. W., Roberts, B. W., \& John, O. P. 1993: The Divided Self: Concurrent and Longitudinal Effects of Psychological Adjustment and Social Roles on Self-Concept Differentiation. Journal of Personality and Social Psychology, 64, 834-846.

Fleeson, W. 2001: Toward a structure- and process-integrated view of personality: Traits as density distribution of states. Journal of Personality and Social Psychology, 80, 10111027.

Fleeson,W. 2004: Moving personality beyond the person-situation debate: The challenge and opportunity of within-person variability. Current Directions in Psychological Science, 13, 83-87.

Geertz, C. (Ed.) 1973: The Interpretation of Culture. New York: Basic Books. 
Querstret and Robinson. Qualitative Research in Psychology, in press.

Gergen, K. J. 1972: Social psychology as history. Journal of Personality and Social Psychology, 26, 309-320.

Gergen, K. J. 2009: An invitation to Social Constructionism (2nd ed.). London: Sage Publications Ltd.

Gerring, J. 2007: Case Study Research: Principles and Practice. New York: Cambridge University Press.

Gilligan, C. 1982. In a Different Voice. Psychological Theory and Women's Development. Harvard University Press.

Goffman, E. 1959. The Presentation of Self in Everyday Life. Anchor Books.

Hanson, W. E., Creswell, J. W., PlanoClark, V. L., Petska, K. S., Creswell, J. D. 2005: Mixed Methods Research Designs in Counseling Psychology. Journal of Counseling Psychology, 52, 224-235.

Harter, S., Bresnick, S., Bouchey, H. A., \& Whitesell, N. R. 1997: The development of multiple role-related selves during adolescence. Development and Psychopathology, 9, 835-853.

Heller, D., Watson, D., Komar, J. A., Min, J. \& Perunvic, W. Q. E. 2007: Contextualised personality: Traditional and New Assessment Procedures. Journal of Personality, 37, 504-528.

Hollis, J. 1993: The middle passage: From misery to meaning in midlife. Toronto: Inner City Books.

Hopcke, R. 1995: Persona. Boston: Shambhala.

Jung, C. G. 1917: 'On the psychology of the unconscious'. Coll. Wks., 7. London: Routledge.

Jung, C. G. 1921: 'Psychological Types'. Coll Wks, 6. London: Routledge.

Jung, C. G. 1928: 'The relations between the ego and the subconscious'. Coll. Wks., 7. London: Routledge.

Laing, R. D. 1960: The Divided Self. New York: Pantheon.

Leary, M. R. 2003: Interpersonal Aspects of Optimal Self-Esteem and the Authentic Self. Psychological Inquiry, 14, 52-54.

Leary, M. R., \& Kowalski, R. M. 1990: Impression Management: A Literature Review and TwoComponent Model. Psychological Bulletin, 107, 34-47.

Maslow, A. H. 1968: Toward a psychology of being. Princeton, New Jersey: Van Nostrand.

McAdams, D. P. 1994: A Psychology of the Stranger. Psychological Inquiry, 5, 145-148.

McAdams, D. 2006: The Redemptive Self: Stories Americans live by. New York: Oxford University Press.

Mertens, D. M. 2003: Mixed methods and the politics of human research: The transformativeemancipatory perspective. In A. Tashakkori \& C. Teddlie (Eds.), Handbook of mixed methods in social and behavioral research (pp. 135-164). Thousand Oaks, CA: Sage.

Meyers, D. T. 1989: Self, Society, and Personal Choice. New York: Columbia University Press.

Mischel, W. 1999: Personality coherence and dispositions in a cognitive-affective personality system (CAPS) approach. In D.Cervone \& Y.Shoda (Eds.) The Coherence of Personality: Social cognitive bases of consistency (pp.37-60). New York: Guilford Press.

Paulhus, D. L., \& Malcolm, C. L. 1988: Functional flexibility: A new conception of interpersonal flexibility. Journal of Personality and Social Psychology, 55, 88-101.

Perlman, H. H. 1968: Persona: Social Role and Personality. University of Chicago.

Riviere, J. 1929: Womanliness as a masquerade. International Journal of Psychoanalysis, 10, 303-313. 
Querstret and Robinson. Qualitative Research in Psychology, in press.

Roberts, B. W., \& Donahue, E. M. 1994: One personality, multiple selves: Integrating personality and social roles. Journal of Personality, 62, 201-218.

Robinson, O.C. 2009: On the Social Malleability of Traits: Variability and Consistency in Big 5 Trait Expression across Three Interpersonal Contexts. Journal of Individual Differences, 30, 201-208.

Robinson, O.C. \& Smith, J.A. 2010a: Investigating the Form and Dynamics of Crisis Episodes in Early Adulthood: The Application of a Composite Qualitative Method. Qualitative Research in Psychology, 7, 170-191.

Robinson, O.C. \& Smith, J.A. 2010b: The Stormy Search for Self in Early Adulthood: Developmental Crisis and the Dissolution of Dysfunctional Personae. The Humanistic Psychologist, 38, 120-145.

Robinson, O.C., Wright, G.R \& Kendall, E. 2011: Parental Attachment and its Relationship to Contextualised Trait Expression and Mean-Corrected Cross-Context Trait Variability. Personality and Individual Differences, 50, 547-552.

Rogers, C. 1959: A theory of therapy, personality, and interpersonal relationships, as developed in the client-centered framework. In S. Koch (Ed.), Psychology: A study of science: Vol. 3. Formulations of the person and the social context (pp. 184-256). New York: McGraw-Hill.

Rogers, C. 1961: On becoming a person. Boston: Houghton Mifflin.

Rowan, J. 1988: Ordinary Ecstasy: Humanistic Psychology in Action, 2nd Edition. London: Routlege.

Sampson, E.E. (1993). Celebrating the Other: A Dialogic Account of Human Nature. Boulder, CO: Westview Press.

Sanford, N. 1956. Surface and depth in personality. Psychological Review, 63, 349-359.

Sheldon, K. M., Ryan, R. M., Rawsthorne, L. J., \& Ilardi, B. 1997: Trait Self and True Self: Cross-Role Variation in the Big-Five Personality Traits and Its Relations with Psychological Authenticity and Subjective Well-Being. Journal of Personality and Social Psychology, 73, 1380-1393.

Suh, E.M. 2002: Culture, Identity Consistency, and Subjective Well-Being. Journal of Personality and Social Psychology, 83, 1378-1391.

Wilkinson, S., Joffe, H., \& Yardley, L. 2004: Qualitative data collection'. In D. Marks and L. Yardley (Eds.), Research Methods in for Clinical and Health Psychology. London: Sage, pp. 39-55.

Winnicott, D. W. (Ed.). 1960: The maturational process and the facilitating environment: Studies in the theory of emotional development. New York: International UP.

Yardley, L. and Bishop, F. 2007: Mixing qualitative and quantitative methods: a pragmatic approach. In C.Willig, Carla and W.Stainton-Rogers (Eds.) The SAGE Handbook of Qualitative Research in Psychology, pp.352-370. Sage Publications Ltd. 


\section{Appendix A: Personality Variability Index (PVI) Calculation Procedure}

For all 112 participants, a personality variability index (PVI) score was calculated, ranging between a minimum of 0 and a maximum of 120 . The higher a person's PVI score, the higher the cross-context variability of their personality was across the three contexts. In order to extract this index, a simple set of calculations was conducted for each individual. Intervals are calculated between contextual scores for each personality item. For example if a person gives scores (out of 7) for Item No. 1 (Extraverted/Enthusiastic) of: 3 (with parents), 5 (with friends), and 6 (with work colleagues), the corresponding differential intervals would be: 2 (parents -friends); 3 (parents - work colleagues); and 1 (friends - work colleagues). These are then added together to give the cross-context variability for the item (in this case $2+3+1=6$ ), and then all item indexes are summed to give the Personality Variability Index (PVI). This then reflects the overall amount of cross-context personality variability across all traits. 


\section{Appendix B: Example interview guide (participant $=$ Frankie $)$}

\section{Questions about questionnaire scores}

\section{Extraverted/enthusiastic}

- The scores you put down on your questionnaire were: 7 for friends and work colleagues, 1 for parents; can you help me understand the difference in scores?

- How do those differences in numbers translate to the way in which you behave in those different contexts? (Can you give me some specific examples of differences in behaviour?)

- What do you think are the reasons for the differences in scores? (Can you tell me a bit about how you feel in those different situations?)

\section{Reserved/quiet}

- The scores you put down on your questionnaire were: 7 for parents, 1 for friends and work colleagues; can you help me understand the difference in scores?

- How do those differences in numbers translate to the way in which you behave in those different contexts? (Can you give me some specific examples of differences in behaviour?)

- What do you think are the reasons for the differences in scores? (Can you tell me a bit about how you feel in those different situations?)

\section{Critical/quarrelsome}

- The scores you put down on your questionnaire were: 1 for all contexts; can you help me understand how the consistency in these scores is reflected in your behaviour in the different contexts

\section{Sympathetic/warm}

- The scores you put down on your questionnaire were: 7 for friends and work colleagues, 1 for parents; can you help me understand the difference in scores?

○ How do those differences in numbers translate to the way in which you behave in those different contexts? (Can you give me some specific examples of differences in behaviour?)

- What do you think are the reasons for the differences in scores? (Can you tell me a bit about how you feel in those different situations?)

\section{Dependable/self-disciplined}

- The scores you put down on your questionnaire were: 7 for all contexts; can you help me understand how the consistency in these scores is reflected in your behaviour in the different contexts?

\section{Disorganised/careless}

- The scores you put down on your questionnaire were: 4 for all contexts; can you talk to me about how this consistency is reflected in your behaviour in each of the contexts?

\section{Anxious/easily upset}

- The scores you put down on your questionnaire were: 7 for parents, 1 for work colleagues and friends; can you help me understand the difference in scores?

- How do those differences in numbers translate to the way in which you behave in those different contexts? (Can you give me some specific examples of differences in behaviour?)

○ What do you think are the reasons for the differences in scores? (Can you tell me a bit about how you feel in those different situations?)

\section{Calm/emotionally stable}

- The scores you put down on your questionnaire were: 7 for friends and work colleagues, 1 for parents; can you help me understand the difference in scores?

- How do those differences in numbers translate to the way in which you behave in those different contexts? (Can you give me some specific examples of differences in behaviour?)

- What do you think are the reasons for the differences in scores? (Can you tell me a bit about how you feel in those different situations?) 


\section{Open to new experiences/complex}

- The scores you put down on your questionnaire were: 7 for all contexts; can you talk to me about how this consistency is reflected in your behaviour in each of the contexts?

\section{Conventional/uncreative}

- The scores you put down on your questionnaire were: 7 for parents, 1 for friends and work colleagues; can you help me understand the difference in scores?

- How do those differences in numbers translate to the way in which you behave in those different contexts? (Can you give me some specific examples of differences in behaviour?)

- What do you think are the reasons for the differences in scores? (Can you tell me a bit about how you feel in those different situations?)

\section{$\underline{\text { Contextual behaviour and felt authenticity questions }}$}

How would you describe yourself when you're around your parents?

- What is it that you think makes you act that way?

- Can you share how you feel when you are with your parents?

How would you describe yourself around your friends?

- Would you mind telling me why you think it is that you act that way?

- Can you explain to me how that comes across in your behaviour?

- Please tell me how you feel when you are with your friends?

$\circ$ Is this consistent with all of your friends?

How would you describe yourself around your work colleagues?

- Can you tell me what you think are the reasons that you behave that way with your work colleagues?

- How do you feel when you are with your work colleagues?

○ Are there any work colleagues you feel differently around?

Do you feel that you put on a front in any of these contexts?

- Can you tell me how it makes you feel?

- Does it bother you?

So, you say you feel least authentic when you are with your [whichever they have said]; how do you think putting on a front changes the traits that we've been talking about?

- Can you give specific examples of what you think would be different if you didn't feel the need to put on a front?

- Which traits do you think are most compromised?

What does it mean to you to 'be yourself'?

- What does 'being authentic' mean to you?

$\underline{\text { Relationship contextual behaviour - not in the questionnaire }}$

- Are you currently in a relationship?

If we had measured these traits with your partner as one of the contexts, what would you have provided?

- If we had asked about extended family (brothers and sisters), what would you have provided?

- Do you feel you can be yourself in these other contexts?

- How does that reveal itself?

- Can you speak about specific behavioural examples? 
Querstret and Robinson. Qualitative Research in Psychology, in press.

Table 1: Participant pseudonyms and details

\begin{tabular}{|c|c|c|c|c|c|c|}
\hline Name & Age & Gender & PVI & Occupation & Marital & Children \\
\hline & & & Score & & Status & $\mathbf{Y} / \mathbf{N}$ \\
\hline Amy & 32 & $\mathrm{~F}$ & 60 & Freelance Musician & Single & $\mathrm{N}$ \\
\hline Brandon & 31 & M & 54 & $\begin{array}{l}\text { Police Community Support } \\
\text { Officer }\end{array}$ & Single & $\mathrm{N}$ \\
\hline Frankie & 37 & $\mathrm{~F}$ & 74 & Manager: Financial services & Married & $\mathrm{N}$ \\
\hline Lily & 39 & $\mathrm{~F}$ & 52 & $\begin{array}{l}\text { Manager: Community Mental } \\
\text { Health }\end{array}$ & Single & $\mathrm{N}$ \\
\hline Malcolm & 35 & M & 52 & TV Weather Presenter & Married & $\mathrm{N}$ \\
\hline Mary & 35 & $\mathrm{~F}$ & 40 & Manager: Hedge Fund & Married & $\mathrm{N}$ \\
\hline Steven & 40 & M & 64 & $\begin{array}{l}\text { Manager: Information } \\
\text { Technology }\end{array}$ & Married & Y \\
\hline Trudy & 39 & $\mathrm{~F}$ & 72 & English Language Teacher & Married & Y \\
\hline
\end{tabular}

NB. All names are aliases 